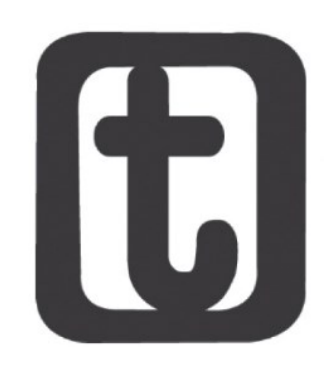

\title{
FISCALIZAÇÃO DO EXERCÍCIO PROFISSIONAL DOS/AS ASSISTENTES SOCIAIS E SUAS PECULIARIDADES
}

\author{
Supervision of the professional exercise of social workers and their peculiarities
}

\section{Micarla de Moura Lima*}

\begin{abstract}
RESUMO
Neste artigo apresentaremos uma breve análise teórico-crítica sobre as peculiaridades da fiscalização do exercício profissional do/a Assistente Social que é a atividade precípua dos Conselhos Federal e Regionais de Serviço Social (CFESS/CRESS). Além de destacar a relevância do trabalho desenvolvido pelos/as Agentes Fiscais que são Assistentes Sociais e estão inseridos/as nestas entidades como trabalhadores e trabalhadoras.
\end{abstract}

\section{PALAVRAS-CHAVE}

Fiscalização. Assistente Social. Agente Fiscal.

\begin{abstract}
In this article, we will present a brief theoretical-critical analysis of the peculiarities of the supervision of the Social Worker's professional practice, which is the main activity of the Federal and Regional Councils of Social Service (CFESS/CRESS). In addition to highlighting the relevance of the work developed by the Fiscal Agents who are Social Workers and are inserted in these entities as workers.
\end{abstract}

\section{KEYWORDS}

Surpervision. Social Worker. Fiscal Agent.

\section{INTRODUÇÃO}

Os Conselhos Regionais de Serviço Social (CRESS) são autarquias públicas federais ${ }^{1}$, cuja função precípua consiste em orientar, disciplinar, fiscalizar e defender o exercício profissional dos/as Assistentes Sociais em sua jurisdição de atuação, articulando suas ações com o Conselho Federal de Serviço Social (CFESS). São também responsáveis por organizar o registro de profissionais e de pessoas jurídicas que desenvolvem atividades no âmbito do Serviço Social e atuam ainda como Tribunais Regionais de Ética, dentre outras funções administrativas, conforme dispõe o Art. 10 da Lei Federal nº 8.662/93 que regulamenta a profissão de Serviço Social no Brasil.

\footnotetext{
* Assistente Social. Mestre em Serviço Social. Agente Fiscal do Conselho Regional de Serviço Social. (CRSS, Natal, Brasil). Av. Rio Branco, 571 , Ed. Barrão do Rio Branco, $9^{\circ}$ Andar, sala 903, Cidade Alta, CEP.: 59025-900, Natal (RN). E-mail: <micarlaml32@gmail.com>.

${ }^{1}$ As autarquias possuem personalidade pública, são autônomas administrativamente e financeiramente e assumem funções de caráter estatal, logo, devem ser criadas por lei específicas.
}

DOI 10.22422/temporalis.2018v18n36p320-335 
O desempenho da função de Agente Fiscal nos CRESS, na qualidade de uma atribuição privativa do/a Assistente Social que faz parte do quadro efetivo de trabalhadores e trabalhadoras do respectivo Regional, tem se tornado um novo espaço sócio-ocupacional de trabalho para os/as Assistentes Sociais no Brasil. Na nossa avaliação, esse espaço vem sendo ampliado a partir da necessidade da expansão das atividades de orientação e fiscalização profissional, não apenas devido ao aumento do número de profissionais inscritos/as, mas também em razão da precarização das relações trabalhistas que afeta os/as Assistentes Sociais enquanto integrantes da classe trabalhadora.

Nesta perspectiva, advogamos que o aprofundamento da precariedade dos serviços somados à insegurança do trabalho e o correspondente aviltamento das condições de trabalho que afetam a classe trabalhadora e em particular os/as Assistentes Sociais, têm requerido uma maior atuação dos CRESS em defesa da categoria e da qualidade dos serviços, demandando ágil e competente atuação do/a Agente Fiscal para o cumprimento da Política Nacional de Fiscalização (PNF) do Conjunto CFESS/CRESS. Destaca-se, assim, a relevância da atuação do/a Agente Fiscal nesse processo, uma vez que, segundo o parágrafo primeiro do Art. 12 da Resolução CFESS nº 512/2007, ele/ela “[...] é um profissional cuja função compreende atribuições políticas, técnicas, operacionais com vistas à consolidação do projeto ético-político do Assistente Social".

Logo, apreendemos que a realidade atual de precarização das condições objetivas de trabalho e de baixos salários que afeta a categoria dos/as Assistentes Sociais no Brasil apresenta repercussão direta ao Conjunto CFESS/CRESS em virtude de serem solicitadas mais ações do conselho em defesa desta categoria como também no não pagamento da anuidade ${ }^{2}$ devida por parte dos/as profissionais impactando fortemente a estrutura de funcionamento dessas entidades. Logo, a partir do que foi exposto, objetivamos apresentar neste artigo uma breve análise teórico-crítica ${ }^{3}$ sobre as peculiaridades da fiscalização do exercício profissional do/a Assistente Social enquanto atividade precípua dos Conselhos Regionais de Serviço Social e destacar a relevância do trabalho desenvolvido pelos/as Agentes Fiscais que são Assistentes Sociais e estão inseridos/as nestas entidades como trabalhadores e trabalhadoras.

\section{A FISCALIZAÇÃO DO EXERCÍCIO PROFISSIONAL DO/A ASSISTENTE SOCIAL ENQUANTO ATIVIDADE PRECÍPUA DO CONJUNTO CFESS/CRESS}

É possível verificar que as mudanças internas ocorridas no âmbito da profissão de Serviço Social nas últimas décadas no Brasil influenciaram diretamente a atuação do Conjunto CFESS/CRESS, especificamente com relação ao seu posicionamento político sobre diversas temáticas, as ações estratégicas realizadas e o próprio direcionamento da Política de Fiscalização durante sua formulação a partir dos anos 1990. A fim de ratificarmos tal entendimento, apresentaremos a seguir um breve histórico do surgimento dos Conselhos de Fiscalização no Brasil e algumas de suas particularidades.

\footnotetext{
${ }^{2} \mathrm{O}$ valor arrecadado com o pagamento da anuidade pelos/as Assistentes Sociais é a única fonte de recurso financeiro utilizada para a manutenção do funcionamento dos CRESS e do CFESS.

${ }^{3}$ A reflexão ora apresentada baseia-se em nossa experiência profissional na condição de Agente Fiscal e em nossa pesquisa de mestrado realizada sobre as condições objetivas de trabalho das Agentes Fiscais dos CRESS da Região Nordeste no ano de 2017.
} 


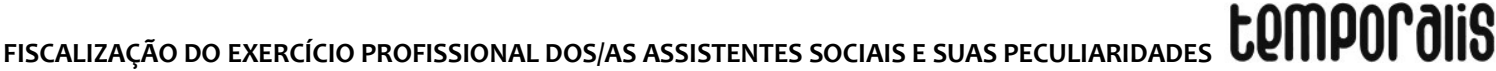

Segundo Pereira (2013a, p. 23), no Brasil, os grêmios podem ser considerados os primeiros modelos de Conselhos de Fiscalização Profissional, sendo baseados em modelos corporativistas, que, aos poucos, foram sendo substituídos. Com a expansão do trabalho livre, o Estado, visando o controle e a manutenção da ordem vigente naquele período, passou a se responsabilizar pela fiscalização das profissões que foram sendo regulamentadas, mantendo a sua tendência intervencionista nas relações sociais num período de grandes mudanças sociais, políticas e econômicas na sociedade brasileira.

Dessa maneira, a partir da década de 1930, o Estado brasileiro começou a descentralizar as suas funções por meio da autorização de criação de pessoas jurídicas de direito público ${ }^{4}$ designadas a fiscalizarem o exercício profissional das profissões que estavam sendo regulamentadas. A primeira entidade que pode ser citada formalmente como representante dos Conselhos de Fiscalização foi a Ordem dos Advogados do Brasil (OAB), criada em 18 de novembro de 1930, concomitante à expansão dos cursos jurídicos pelo país na época. Assim, segundo Pereira (2013a, p. 28),

Criada a Ordem dos Advogados do Brasil, outras categorias profissionais começaram a se mobilizar, impulsionadas pelo crescimento do mercado de trabalho e pela efervescência dos cursos superiores que se espalhavam pelo Brasil. Com o tempo, assim, foram surgindo outros conselhos, como os de Contabilidade, Economia, Medicina e Odontologia, entidades que proliferaram e assumiram aos poucos papel de destaque no cenário nacional. (PEREIRA, 2013a, p. 28).

Embora o Serviço Social tenha sido reconhecido como profissão liberal pelo Ministério do Trabalho por meio da Portaria $n^{\circ} 35$ de 19 abril de 1949, a regulamentação do exercício profissional só foi conquistada com a aprovação da Lei de $n^{\circ} 3.252$, de 27 de agosto de 1957 que, por sua vez, só foi validada pelo Decreto $\mathrm{n}^{\circ}$ 994, de 15 de maio de 1962 . Tais acontecimentos revelam as enormes dificuldades de transitar da condição de uma atividade estruturada como voluntariado para um exercício profissional regulamentado e reconhecido como trabalho assalariado passível de fiscalização do seu exercício e normatização de sua conduta profissional.

Note-se que a Lei $n^{\circ}$ 3.252/1957 trouxe a institucionalização dos Conselhos Federal e Regionais ${ }^{5}$ de Fiscalização da Profissão de Serviço Social no Brasil e as suas respectivas funções naquela época. Foram denominados como C. F. A. S. (Conselho Federal de Assistentes Sociais) e C. R. A. S (Conselhos Regionais de Assistentes Sociais).

Os Conselhos de Fiscalização foram criados com o objetivo de exigir a inscrição dos/as novos/as profissionais inseridos/as no mercado de trabalho e de realizar a devida cobrança do tributo obrigatório (anuidade) pelo exercício profissional desenvolvido. Segundo Abreu

\footnotetext{
4 "Os conselhos de fiscalização profissional são pessoas jurídicas, ou seja, são organizações ou unidades de pessoas naturais ou de patrimônios para a consecução de determinados fins, aos quais a ordem jurídica confere identidade própria, direitos e deveres (personalidade e capacidade jurídica), reconhecendo-as, pois, como sujeitos de direitos e obrigações" (PEREIRA, 2013b, p.30).

5 "[...] o conselho federal e os conselhos regionais vinculavam-se diretamente à legislação federal, que alinhava a responsabilidade da habilitação profissional ao Ministério do Trabalho, e a do ensino aos dispositivos emanados pelo Ministério da Educação e Cultura, que os reconheciam como instâncias máximas de fiscalização do exercício profissional" (MOURÃO, 2003, p. 45).
} 
(2012), no âmbito do Serviço Social, “[...] a regulamentação da profissão de Assistente Social seguiu a tendência regulatória e intervencionista do Estado brasileiro, num contexto de mudanças sociais e econômicas marcado pelo reordenamento do capitalismo" (ABREU, 2012, p. 57). Nesse sentido,

[...] a criação das entidades de fiscalização no âmbito do Serviço Social coincidirá com um período do desenvolvimento da profissão, que expandia seus espaços ocupacionais e trilhava novos caminhos para sua consolidação nos meios profissionais e acadêmicos. Lembremos que o período era de questionamento das bases tradicionais do serviço social, quando já se vislumbravam condições que sinalizam o processo de erosão do serviço social tradicional (ABREU, 2012, p. 58).

Não por mera coincidência, mesmo com esse processo de renovação da profissão, os Conselhos de Serviço Social mantiveram suas ações numa perspectiva conservadora até meados da década de 1980, ainda que permeada por tensões e esforços dos grupos progressistas da categoria no sentido de realizar as modificações necessárias em nossas legislações naquele período.

Dentre os esforços, destacamos, a realização de Encontros Nacionais anualmente pelo Conjunto CFESS/CRESS a partir do ano de $1966^{6}$ para discutir suas pautas de atuação no exercício seguinte. É nesse evento que são realizados acertos de determinadas ações da Fiscalização em âmbito nacional e a tomada de posições políticas sobre determinadas temáticas, além da aprovação de Resoluções administrativas e/ou para orientação da categoria em sua atuação profissional. Assim, os Encontros Nacionais passaram a ser a instância máxima de deliberações da categoria e, até o momento, já foram realizadas 46 edições.

Note-se que à medida que a direção social do movimento CFESS/CRESS se alinhava ao Projeto Societário da classe trabalhadora houve a mobilização da categoria para imprimir mudanças no modo de atuação dos Conselhos Federal e Regionais e, igualmente, a própria concepção de Fiscalização que deveria ser realizada, a partir desse momento.

Assim sendo, entre os anos 1980 e 1990, com o desenvolvimento e amadurecimento intelectual 7 da profissão, as entidades da categoria verificaram a necessidade de uma adequação, também, das ações da fiscalização para além das simples atividades burocráticas e normativas já realizadas, buscando, agora, atender mais as demandas provenientes do cotidiano dos/as Assistentes Sociais, o fortalecimento do compromisso ético com os/as usuários/as dos serviços e aliando-se as bandeiras de lutas da classe trabalhadora em defesa da efetivação de direitos.

A partir desse período, o Conselho Federal buscou apresentar maior transparência à categoria sobre a aplicabilidade financeira dos recursos arrecadados a partir da cobrança das anuidades. Ademais, o conjunto de profissionais participantes do Encontro Nacional aprovou a obrigatoriedade de realização de eleições diretas de 03 em 03 anos para as

\footnotetext{
${ }^{6}$ Período de plena resistência diante do Regime da Ditadura Militar que se fortalecia no Brasil.

7 Cabe destacarmos que a aproximação com a Teoria Social Crítica de Marx possibilitou a consolidação do amadurecimento intelectual da profissão que vinha sendo fomentado no âmbito da profissão a partir da leitura crítica e de totalidade da realidade, contribuindo assim a configuração de um novo perfil profissional no âmbito da categoria.
} 


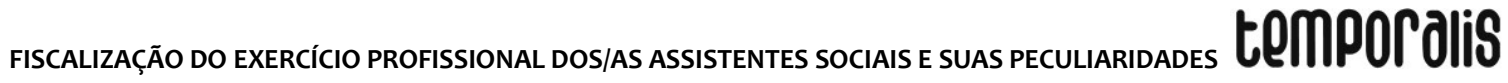

Direções do C.F.A.S e dos C.R.A.S a partir do ano de 1987, com voto não obrigatório para os/as profissionais, demostrando a preocupação em democratizar as ações do conjunto (VINAGRE, 2009). Deste modo,

[...] sintonizada com as lutas pela redemocratização da sociedade, parcela da categoria profissional, vinculada ao movimento sindical e às forças mais progressistas, se organiza e disputa a direção dos Conselhos Federal e Regionais, com a perspectiva de adensar e fortalecer esse novo projeto profissional. Desde então, as gestões que assumiram o Conselho Federal de Serviço Social imprimiram nova direção política às entidades, por meio de ações comprometidas com a democratização das relações entre o Conselho Federal e os Regionais, bem como articulação política com os movimentos sociais e com as demais entidades da categoria, e destas com os profissionais (CFESS, 2016).

Apesar de todas as discussões e modificações realizadas no âmbito interno do conjunto C.F.A.S/C.R.A.S ainda não se tinha uma normativa para a realização das ações de fiscalização a nível nacional. Enfim, em 1980 foi elaborada a Resolução C.F.A.S n 135 , que tratava da criação da Comissão de Fiscalização dentro dos Conselhos (COFI) e da inserção do/a Assistente Social enquanto Agente Fiscal para ser o/a profissional responsável pelas atividades da fiscalização no âmbito dos C.R.A.S, caracterizando-se, deste modo, como uma normativa que possibilitou, a princípio, a unificação das ações dos Conselhos no âmbito da Fiscalização a nível nacional (ABREU, 2012).

Portanto,

[...] com o respaldo dessa normativa os Conselhos Regionais implantaram os primeiros serviços e/ou comissões de fiscalização e desencadearam as primeiras experiências de fiscalização, inicialmente voltadas à organização administrativofinanceira, entendida como suporte fundamental às ações da fiscalização, avançando para a identificação da categoria, conhecimento da realidade institucional, das condições de trabalho, autonomia, defesa de espaço profissional, atribuições e capacitação, assim como a necessária articulação política do Conjunto com outros sujeitos coletivos (ABREU, 2012, p. 59 apud CFESS, 2008).

De tal modo, verificamos que as décadas de 1980 e 1990, enfim, foram períodos de bastante amadurecimento teórico para a categoria, refletindo, consequentemente, nas legislações que respaldam a categoria como a aprovação do Código de Ética de 1986 que trouxe avanços quanto a negação da base conservadora tradicional, ainda que apresentasse necessidade das adequações realizadas em 1993 com a aprovação de um novo Código ${ }^{8}$ e, também, com a nova Lei de Regulamentação, que expressam o amadurecimento da categoria.

De acordo com Abreu (2012, p. 61) a aprovação da nova legislação "[...] assegurou à fiscalização profissional possibilidades mais concretas de intervenção, pois a lei definiu com maior precisão as competências e atribuições privativas do Assistente Social”. A partir dessa nova legislação, enquanto conquista e expressão do amadurecimento político da categoria, no âmbito do conjunto CFESS/CRESS, a fiscalização

\footnotetext{
${ }^{8}$ Cabe ressaltar que a profissão ao longo de seu desenvolvimento e amadurecimento teórico elaborou 05 (cinco) Códigos de Ética para orientação da categoria, nos respectivos anos: 1947, 1965, 1975, 1986 e 1993 (em vigência).
} 
[...] passou por um processo de ampliação e renovação de sua concepção, pois deixou de ter um caráter meramente disciplinador, adquirindo uma dimensão político-pedagógica que evidencia o compromisso da categoria com a qualidade dos serviços prestados enquanto direitos sociais historicamente conquistados [...] (SANTOS et al, 2010, p.148).

Nessa direção, a aprovação da Política Nacional de Fiscalização ${ }^{9}$ (PNF) no ano de 1999 através da Resolução CFESS $n^{\circ} 382$ também possibilitou melhorias para a efetivação da fiscalização do exercício profissional dos/as Assistentes Sociais no país a partir da unificação de ações estratégicas, políticas e jurídicas em resposta às novas demandas sociais recebidas. Essa Resolução foi revisada e alterada pela Resolução CFESS n 512/07 que ainda se encontra em vigência. Nesta perspectiva, devemos compreender que

[...] o exercício de construção dessa política junto aos Conselhos Regionais contribuiu para a consolidação da democracia interna no âmbito do conjunto dos Conselhos, ao assinalar que a fiscalização profissional deve assegurar a qualidade dos serviços prestados à população, salvaguardando os interesses desta, e que o ato de fiscalizar deve ser exercido também como um instrumento de capacitação e de organização da categoria profissional, sempre voltado para o aprimoramento do papel social de natureza pública da profissão (MOURÃO, 2003, p. 55).

Portanto, defendemos que a fiscalização do exercício profissional dos/as Assistentes Sociais deve ser compreendida como uma ação estratégica para o fortalecimento da categoria articulando suas bandeiras de lutas às da classe trabalhadora por melhores condições salariais e objetivas de trabalho e não apenas como uma mera execução de ações normativas do Conjunto CFESS/CRESS, sem expressar um direcionamento político.

Nesse sentido, ao mesmo tempo, ela contribui para o fortalecimento do projeto éticopolítico da nossa profissão que visa a superação da ordem societária atual por uma sociedade que possibilite a garantia de direitos e a plena emancipação humana ${ }^{10}$, sendo esta uma das diretrizes para a execução da PNF. Portanto, reiteramos

[...] a concepção de fiscalização assumida na PNF supera a perspectiva corporativa da organização política quando investe na defesa das políticas públicas e na preocupação com a qualidade dos serviços prestados à população, o que, por sua vez, impacta as condições e relações de trabalho em que se inserem os assistentes sociais (SANTOS et al., 2010, p. 157).

Por conseguinte, compreendemos que o/a Agente Fiscal desempenha papel importantíssimo nesse processo de execução e consolidação da PNF e de defesa da categoria profissional e, por isso, a próxima seção será dedicada à discussão acerca dos

\footnotetext{
${ }^{9}$ Ressalte-se que a PNF está organizada nos seguintes eixos: I. Potencialização da ação fiscalizadora para valorizar, defender, fortalecer e publicizar a profissão; Il. Capacitação técnica e política dos agentes fiscais e demais membros das COFIs para o exercício da orientação e fiscalização; III. Articulação programática entre CFESS/CRESS, ABEPSS, ENESSO, Unidades de Ensino e representações locais de estudantes; IV. Inserção do Conjunto CFESS/CRESS nas lutas em defesa da ampliação e garantia dos direitos, das políticas sociais e da democracia na direção de uma sociedade igualitária.

10 "É possível, então, a emancipação humana? Acreditamos que sim e, mais que isso, ela é necessária porque a forma de sociabilidade subsumida ao capital converteu-se em uma ameaça à continuidade da humanidade e por isso precisa ser superada se a humanidade quiser seguir em sua aventura" (IASI, 2013, p. 60).
} 


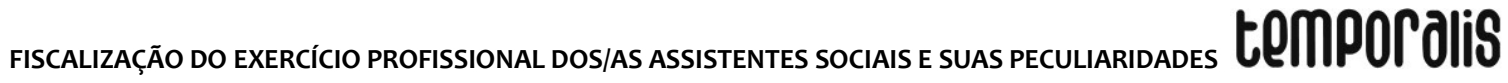

principais aspectos que caracterizam a inserção e a atuação desse/a profissional nos CRESS que, enquanto trabalhadoras e trabalhadores assalariados/as, necessitam também de condições adequadas (éticas, técnicas, salariais) para a realização do seu trabalho com qualidade.

\section{O/A AGENTE FISCAL ENQUANTO TRABALHADOR/A ASSALARIADO/A E AS PECULIARIDADES DO SEU TRABALHO NA REALIDADE DOS CRESS}

Os/as Agentes Fiscais são inseridos/as nos CRESS através de aprovação em Concurso Público ${ }^{11}$, uma vez que devem ser funcionários/as do Regional, conforme dispõe a Política Nacional de Fiscalização (PNF). Entendemos que tal fato demonstra tanto uma conquista democrática de que os Conselhos Profissionais se pautem por processos republicanos de admissão de pessoal, quanto revela a condição de trabalhador/a assalariado/a do/a Assistente Social vendedor/a da sua força de trabalho a um empregador (nesse caso, ao CRESS) ao assumir a função de Agente Fiscal em troca de um salário mensal para atender as suas necessidades básicas de vida.

Desta maneira, seu exercício inclui peculiaridades tais como participar da Comissão de Orientação e Fiscalização (COFI), uma vez que a Resolução CFESS n 512/07 dispõe que tal comissão deve ser composta por: 01 (um/a) conselheiro/a que seja coordenador/a da Comissão, Agentes Fiscais e profissionais da base que desejam e são convidados/as a participarem ${ }^{12}$. Em nossa avaliação essa prerrogativa coloca esse/a trabalhador/a em uma condição que confere um alargamento da sua autonomia e uma dinâmica de trabalho que não se baseia em subalternidade comum à condição de empregado/a diante do/a seu/sua empregador/a.

É importante destacar que os/as conselheiros/as eleitos/as para a diretoria são considerados/as fiscais natos, podendo identificar situações de irregularidade e fazer orientações sobre a resolutividade da questão ou comunicar à COFI para os devidos encaminhamentos, contudo os/as conselheiros/as não possuem a condição de assalariamento que o/a Agente Fiscal possui enquanto trabalhador/a do conselho, não podendo, assim, assumir completamente as funções que devem ser desempenhadas pelo/a ocupante do cargo.

Todavia, a PNF não estabelece um número mínimo de fiscais por CRESS, concorrendo para que, em geral, as diretorias utilizem como critério as condições financeiras para a contratação ou não de mais Agentes Fiscais. Deste modo, reconhecidamente, a maioria dos conselhos apresenta uma quantidade de profissionais que é insuficiente para atender todas as demandas recebidas pelo Regional nos últimos anos, acarretando assim uma sobrecarga de trabalho. Esse fato imputa um ônus que reproduz a própria situação comum

\footnotetext{
${ }^{11}$ Destacamos que a defesa da realização de concursos públicos pelas instituições para contratação de Assistentes Sociais é uma das Bandeiras de Lutas em defesa da profissão pautadas pelo Conjunto CFESS/CRESS. O referido documento pode ser acessado através do seguinte link: CFESS-CRESS. Sou assistente social e aqui estão minhas bandeiras de luta!: conheça a pauta política do serviço social brasileiro construpida coletivamente ao longo dos últimos anos pelo conjunto Conselho Federal de Serviço SocialConselhos Regionais de Serviço Social (2017).

${ }^{12}$ Vale ressaltar que a assessoria jurídica dos CRESS, também, participa das reuniões da COFI quando se discute casos que se necessita de orientação sobre procedimentos jurídicos a serem adotados.
} 


\section{tempordilis}

ao conjunto dos trabalhadores e das trabalhadoras, particularmente aos/às Assistentes Sociais.

Note-se que o aumento da oferta de Cursos de Graduação em Serviço Social na última década no Brasil, principalmente, na modalidade à distância contribuiu consideravelmente para o aumento de profissionais inscritos/as nos CRESS. Além disso, a intensificação da precarização das políticas sociais e, por conseguinte, das condições de trabalho dos/as Assistentes Sociais tem exigido uma maior atuação política e jurídico-normativa dos conselhos em defesa da nossa profissão e da qualidade dos serviços prestados à população usuária nos diversos espaços sócio-ocupacionais.

Assim, entendemos que a insuficiência do número de trabalhadores e trabalhadoras nos CRESS para atendimento de todas as demandas tem relação com a precária condição financeira da maior parte dos regionais que enfrentam um alto índice de inadimplência por parte dos/as profissionais. Devemos elucidar que a anuidade constitui-se em um tributo obrigatório estabelecido pelo Estado e instituído pela Lei de regulamentação da profissão tendo como objetivo promover a manutenção do conselho e o desenvolvimento de suas funções político-administrativas.

Então, avaliamos que uma das razões para o alto índice de inadimplência tenha relação direta com os baixos salários pagos à maioria dos/as Assistentes Sociais que enquanto trabalhadores/as assalariados/as também sofrem diretamente com as precárias e instáveis novas relações trabalhistas. Questão essa que requer maior investigação e análise que não constitui objeto deste estudo, embora as dificuldades financeiras dos CRESS tenha forte implicações nas condições de funcionamento dos conselhos e, portanto, nas condições de trabalho e do patamar salarial dos/as Agentes Fiscais.

Essa situação tem preocupado a direção do conjunto CFESS/CRESS que tem buscado problematizar tal realidade e dimensioná-la, inclusive através da realização de pesquisas, tais como o estudo desenvolvido pela entidade sobre a taxa de inadimplência nos Regionais em dezembro de 2015. Os dados identificados nessa pesquisa revelam que naquele período alguns CRESS apresentaram índice de inadimplência acima de 50\% do número de profissionais ativos/as, estando a maioria dos CRESS da Região Nordeste entre os que exibem maiores taxas de inadimplência, conforme se pode observar na seguinte tabela: 


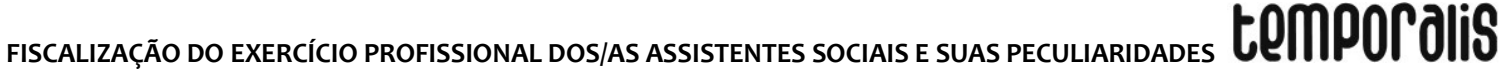

Tabela 01 - Inadimplência por CRESS - Ano 2015

\begin{tabular}{|c|c|c|c|}
\hline CRESS & Profissionais Ativos & $\begin{array}{l}\text { Profissionais em situação } \\
\text { de inadimplência }\end{array}$ & $\%$ \\
\hline CRESS 1a Região PA & 6.763 & 3.213 & 47,50 \\
\hline CRESS 2ạ Região MA & 3.982 & 1.317 & 33,07 \\
\hline CRESS 3ạ Região CE & 7.154 & 3.163 & 44,21 \\
\hline CRESS 4ạ Região PE & 5.836 & 2.392 & 40,90 \\
\hline CRESS 5ạ Região BA & 12.754 & 2.885 & 22,62 \\
\hline CRESS 6ạ Região MG & 14.969 & 3.635 & 24,28 \\
\hline CRESS 7ạ Região RJ & 16.345 & 4.023 & 24,61 \\
\hline CRESS 8a Região DF & 2.070 & 1.092 & 52,75 \\
\hline CRESS 9ạ Região SP & 31.638 & 5.595 & 17,68 \\
\hline CRESS 10a Regiăo RS & 7.481 & 2.713 & 36,26 \\
\hline CRESS 11a Região PR & 7.535 & 2.660 & 35,30 \\
\hline CRESS 12ạ Região SC & 4.782 & 734 & 15,34 \\
\hline CRESS 13ạ Região PB & 3.874 & 2.655 & 68,53 \\
\hline CRESS 14ạ Região RN & 2.981 & 2.001 & 67,12 \\
\hline CRESS 15ạ Região AM/RR & 6.359 & 2.844 & 44,72 \\
\hline CRESS 16ạ Região AL & 3.168 & 1.641 & 51,79 \\
\hline CRESS 17ạ Região ES & 4.671 & 1.447 & 30,97 \\
\hline CRESS 18a Região SE & 2.318 & 1.595 & 68,80 \\
\hline CRESS 19ạ Região GO & 3.732 & 1.479 & 39,63 \\
\hline CRESS 20a Região MT & 3.254 & 2.069 & 63,58 \\
\hline CRESS 21a Região MS & 2.983 & 713 & 23,90 \\
\hline CRESS 22a Região PI & 2.812 & 1.803 & 61,11 \\
\hline CRESS 23ạ Região RO & 1.398 & 744 & 53,21 \\
\hline CRESS 24ạ Região AP & 709 & 478 & 67,41 \\
\hline CRESS 25ạ Região TO & 2.062 & 957 & 46,41 \\
\hline CRESS 26ạ Região AC & 1.431 & 858 & 59,95 \\
\hline Total & 163.061 & 54.706 & 33,54 \\
\hline
\end{tabular}

Fonte: CFESS (2017).

Os dados apresentados acima sobre o percentual de inadimplência nos Regionais do Brasil são alarmantes e certamente aqueles com maior índice possuem as suas receitas comprometidas impactando diretamente nos gastos financeiros elementares para seu funcionamento tais como: o pagamento de funcionários/as, contas de manutenção dos prédios em que funcionam, compra de materiais de expediente e demais gastos que se relacionam a realização de atividades administrativas e no âmbito da fiscalização profissional.

Por conseguinte, é perceptível identificar que uma parte significativa dos/as Assistentes Sociais, em pleno exercício profissional, não tem conhecimento sobre a natureza jurídica da anuidade e o motivo do seu pagamento, fato que faz com que decidam não pagar, visto que eles/elas não recebem um benefício direto ao se inscreverem no conselho. Essa situação revela ainda que desconhecem as devidas atribuições do CRESS enquanto órgão público que autoriza e fiscaliza o exercício profissional ao confundirem com um sindicato no qual possuem a livre escolha de se associarem ou não. 
Dessa maneira, é imprescindível a manutenção de constante realização de atividades político-pedagógicas ${ }^{13}$ de orientação a estudantes e aos/às profissionais que estão se inscrevendo no Conselho a fim de esclarecer a real função da entidade que é representativa da categoria no Estado, além da convocação da base para a participação nas comissões temáticas e nas demais atividades realizadas pelo regional.

Logo, a insuficiência de recursos financeiros impacta nas condições de cumprimento da Resolução CFESS $n^{\circ}$ 512/07 que preconiza em seus artigos $8^{\circ}$ e $9^{\circ}$ a importância da garantia de recursos financeiros e humanos pelos CRESS para a manutenção e a estruturação técnica e operativa visando o desenvolvimento das ações de fiscalização na determinada jurisdição, a saber:

Art. $8^{\circ}$ - Para atuação da COFI, os CRESS deverão garantir uma estrutura adequada aos requisitos técnicos e operacionais necessários à viabilização da PNF.

Art. $9^{\circ}$ - Para execução e concretização da atuação técnico-política da COFI, os CRESS deverão priorizar ações que viabilizem meios e recursos financeiros para estruturação de um serviço de orientação e fiscalização, integrado por agente fiscal e funcionários administrativos que responderão pelas demandas rotineiras do setor, em cumprimento ao plano de ação definido pela COFI e de sua organização administrativa, sempre sob a direção dessa Comissão (CONSELHO FEDERAL SERVIÇO SOCIAL, 2007).

Acrescente-se que a referida resolução estabelece tanto as atribuições que competem a COFI de maneira geral como, também, especifica aquelas de responsabilidade do/a Agente Fiscal, nos Artigos 11 e 13, respectivamente. Dentre as atividades do/a Agente Fiscal, destacam-se:

$\checkmark$ Realizar visitas de fiscalização de rotina e, também, para a verificação de possíveis irregularidades;

$\checkmark$ Elaborar relatórios após as visitas realizadas constatando os fatos identificados;

$\checkmark$ Assessorar a Diretoria quanto a questões sobre o exercício profissional; fiscalização de concursos e processos seletivos com vagas para Assistente Social;

$\checkmark$ Propor e realizar atividades preventivas de orientação e discussão junto a categoria e instituições;

$\checkmark$ Verificar as atribuições desenvolvidas pelos/as Assistentes Sociais durante as visitas;

$\checkmark$ Verificar as condições físicas, técnicas e éticas no exercício profissional do/a assistente social, baseando-se nas normativas do Conjunto CFESS/CRESS;

$\checkmark$ Supervisionar estágio.

\footnotetext{
${ }^{13}$ Nesse sentido, a Política Nacional de Enfrentamento à Inadimplência do Conjunto CFESS/CRESS lançada no início do ano de 2017 traz diversas orientações de atuação dos regionais nos âmbitos Administrativofinanceiro, Política de Comunicação, Política de Orientação e Fiscalização Profissional e da Política de Educação Permanente, sendo, então, um importante material de auxílio para a realização de ações de prevenção e enfrentamento à inadimplência, colocando como prioridade as intervenções políticopedagógicas.
} 


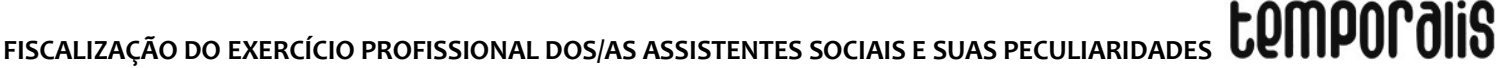

Para realizar essas atividades se faz necessário conhecer plenamente os instrumentais normativos desenvolvidos pelo Conjunto CFESS-CRESS e que servem de base legal para o respaldo das ações realizadas, como a própria Lei 8.662/93, o Código de Ética Profissional de 1993, pareceres jurídicos elaborados pela Assessoria Jurídica do CFESS e as Resoluções que versam sobre inúmeras temáticas que perpassam o exercício profissional dos/as Assistentes Sociais, como a supervisão direta de Estágio, condições éticas e técnicas de trabalho, lacração de material técnico sigiloso, elaboração de laudos e pareceres em conjunto, dentre outras.

De tal modo, em seu cotidiano profissional, o/a Agente Fiscal deve estar em processo de capacitação permanente, já que a categoria continuamente solicita informações e orientações pertinentes às diversas áreas de atuação. E a própria PNF prevê em seu segundo eixo de atuação a "capacitação técnica e política dos agentes fiscais e demais membros das COFIs para o exercício da orientação e fiscalização”.

A função precípua do CRESS é a fiscalização do exercício profissional do/a Assistente Social a partir, principalmente, da realização de visitas às instituições que possuem esse profissional em seu quadro técnico de funcionários/as a fim de verificarmos se ele/ela está adequado às normativas que regem a profissão. E, ao mesmo, aproveitamos para analisarmos as condições éticas e técnicas de trabalho que as entidades empregadoras oferecem aos Assistentes Sociais na perspectiva de defesa da profissão e da qualidade dos serviços prestados à população usuária.

Porém, a maioria dos/as Assistentes Sociais não procura o CRESS para que ele faça visita para fiscalizar o seu exercício profissional e sim para tentarmos adequar e/ou melhorar alguma situação vivenciada em seus locais de trabalho. Em geral, os/as profissionais relatam que mesmo realizando uma articulação/conversa com a gestão da instituição nada é resolvido até que o Conselho faça a fiscalização e notifique-a sobre as irregularidades encontradas e solicite um retorno, em prazo estabelecido, das providências tomadas. Então, eles/elas muitas vezes procuram os serviços do CRESS acreditando que esta é a única alternativa para resolução da situação inadequada.

Logo, as visitas de fiscalização são realizadas para a verificação de denúncias recebidas ou de rotina naquelas instituições que ainda não foram visitadas ou que faz tempo que receberam a fiscalização. Além disso, quando necessário, também são realizadas visitas apenas para orientação e esclarecimentos para os/as profissionais, visando, deste modo, desenvolver ações político-pedagógicas, conforme preconiza a PNF.

Note-se que o/a Agente Fiscal é o/a representante da COFI que, geralmente, tem o primeiro e maior contato com as diversas demandas solicitadas pela categoria profissional aos CRESS. Em alguns momentos, a depender da solicitação, o/a Agente Fiscal já realiza uma orientação ao/à profissional de como proceder a partir da problemática exposta; em outros é necessário apresentar a situação aos/às demais representantes da COFI ou para a diretoria para ser verificada a possibilidade de intervenção do CRESS e qual o caminho mais adequado a ser seguido. Destaca-se que muita das vezes a Comissão opta por realizar ações de caráter político junto as instituições utilizando como respaldo os aparatos jurídicos-normativos que legitimam a profissão ao invés de acionar diretamente a justiça que geralmente apresenta um prazo maior para dar resolutividade as questões. 
Portanto, os/as Agentes Fiscais se apresentam como um elo constante entre a categoria e os membros das diretorias do CRESS, a partir do repasse das demandas recebidas diariamente. Ressalta-se que de três em três anos há uma rotatividade dos/as integrantes das Comissões que funcionam no conselho tendo em vista que uma nova gestão toma posse. Nesse processo as ações que são deliberadas a nível nacional e estão no planejamento continuam sendo executadas independentemente desse processo de mudança interna, porém a nova diretoria tem a autonomia de escolher as novas atividades que serão realizadas a partir de então, mas sem deixar de acolher os anseios apresentados pela categoria dos/as Assistentes Sociais. Dessa maneira, os/as Agentes Fiscais, no âmbito da COFI, são responsáveis pela continuidade de ações básicas e positivas desenvolvidas desde outras gestões e por assessorar os novos membros da referida Comissão sobre as peculiaridades das demandas recebidas, metodologias e procedimentos de trabalho e sobre a legislação que respalda as ações do conselho.

Enfatizamos que a quantidade de demandas que chegam para a COFI tem aumentado bastante nos últimos anos e isso se traduz em alguns regionais na sobrecarga de trabalho para os/as fiscais, já que cada situação, em geral, exige mais de um encaminhamento/atividade que permitirá a resolutividade das questões apresentadas. As principais demandas recebidas pelas COFIs são: Orientações sobre como proceder em caso de solicitações provenientes do Poder Judiciário acerca de estudo social; Recebimento de denúncias relacionadas ao descumprimento da Resolução CFESS N 493/2006; Denúncias de Assistentes Sociais desenvolvendo atribuições incompatíveis a Lei Federal 8.662/1993; Questões relacionadas a estágio em Serviço Social, carga horária e condições de trabalho.

Considere-se que o/a Agente Fiscal atua bastante com questões relacionadas às condições éticas e técnicas de trabalho dos/as Assistentes Sociais, utilizando como respaldo jurídico as orientações instituídas na Resolução CFESS n 493/06 que estabelece parâmetros mínimos e dá outras orientações para a realização das atividades do Serviço Social, sobretudo, os atendimentos aos/às usuários/as que exigem a garantia do sigilo das informações prestadas, destacando-se os seguintes artigos:

Art. $1^{\circ}$ - É condição essencial, portanto obrigatória, para a realização e execução de qualquer atendimento ao usuário do Serviço Social a existência de espaço físico, nas condições que esta Resolução estabelecer.

Art. $2^{\circ}$ - O local de atendimento destinado ao assistente social deve ser dotado de espaço suficiente, para abordagens individuais ou coletivas, conforme as características dos serviços prestados, e deve possuir e garantir as seguintes características físicas:

a- iluminação adequada ao trabalho diurno e noturno, conforme a organização institucional;

b- recursos que garantam a privacidade do usuário naquilo que for revelado durante o processo de intervenção profissional;

c- $\quad$ ventilação adequada a atendimentos breves ou demorados e com portas fechadas;

d- espaço adequado para colocação de arquivos para a adequada guarda de material técnico de caráter reservado.

Art. $3^{\circ}-O$ atendimento efetuado pelo assistente social deve ser feito com portas fechadas, de forma a garantir o sigilo (CONSELHO FEDERAL SERVIÇO SOCIAL, 2006). 


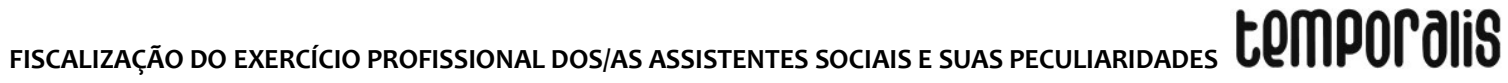

Chamamos a atenção para o fato de que o/a Assistente Social, que assume o cargo de Agente Fiscal nos conselhos, assim como os/as demais profissionais da categoria inseridos/as em outros espaços sócio-ocupacionais, necessita ter à sua disposição condições adequadas de trabalho, como um espaço adequado para a realização de suas funções, salário condizente com a função e possiblidades de crescimento na carreira profissional mediante um Plano de Cargos, Carreira e Remuneração.

Portanto, requer no mínimo dispor das seguintes garantias básicas para um pleno exercício profissional: Garantia do sigilo das informações ${ }^{14}$ durante os atendimentos, conforme institui a normativa acima mencionada; Remuneração condizente com as funções desempenhadas e demais benefícios que o/a permitam construir uma carreira profissional no CRESS que está inserido/a, uma vez que é um/a profissional concursado/a ${ }^{15}$ justamente com o objetivo da manutenção da continuidade das ações desenvolvidas pela Comissão de Orientação e Fiscalização.

De tal modo, compreendemos que os dispêndios financeiros com questões relacionadas à fiscalização, incluindo as ligadas às condições de trabalho, devem ser sempre priorizados no âmbito dos Regionais, uma vez que é sua função precípua. Para tanto deve ocorrer o planejamento do orçamento que deverá ser utilizado durante o ano em exercício, conforme dispõe o Art. 14 da Resolução CFESS nº 512/07, a saber:

Art. 14 - Os CRESS deverão prever, anualmente em seu orçamento, os recursos necessários ao pagamento das despesas com a Comissão de Orientação e Fiscalização.

Parágrafo Único - Quando as despesas excederem o orçamento, o CRESS garantirá a prioridade da fiscalização do exercício profissional no conjunto das suas ações (CONSELHO FEDERAL SERVIÇO SOCIAL, 2006).

Nesse sentido, consideramos ser de extrema relevância que as peculiaridades do trabalho desse/a profissional sejam consideradas visando a estruturação de condições de trabalho condizentes com o que se preconiza nas normativas do Conjunto CFESS/CRESS. Essa é uma luta que perpassa a classe trabalhadora no geral nos mais diversos campos de atuação, mas que, também, alcança esse grupo de profissionais. Dessa maneira, concordamos com Boschetti (2011, p. 564) que

[...] a defesa de condições éticas e técnicas de trabalho para os/as assistentes sociais se soma às lutas sociais e ao fortalecimento dos movimentos sociais da classe trabalhadora. Os desafios postos ao trabalho profissional não são exclusivos da nossa profissão, e somente as lutas coletivas em defesa da classe

\footnotetext{
${ }^{14}$ Destaca-se que a garantia do sigilo das informações é importante durante os atendimentos no CRESS, uma vez que é uma instituição que possui um quadro técnico de servidores/as diversificado no qual só os/as Agentes Fiscais são Assistentes Sociais e uma boa parte das demandas envolvem questões éticas que não podem ser do conhecimento de todos. Além disso, os/as profissionais atendidos/as se sentem mais acolhidos/as quando verificam que podem falar abertamente sobre a problemática vivenciada e não há outras pessoas que não fazem parte do atendimento ouvindo o que é conversado.

${ }^{15} \mathrm{~A}$ investidura nos cargos em Conselhos deve se dá através de Concurso Público, no entanto, o regime a que os/as servidores/as estão submetidos é o celetista, regido pela Consolidação das Leis Trabalhistas (CLT), sendo esta, ainda, uma questão de impasse entre alguns órgãos federais, uma vez que alguns entendem que os Conselhos por serem autarquias, o regime dos seus servidores deveria ser o estatutário, visando garantir estabilidade e carreira a esses e outra parte nega esse entendimento.
} 
trabalhadora podem provocar mudanças nas condições de vida e de trabalho daqueles que dependem da venda de sua força de trabalho para assegurar a produção e a reprodução de suas vidas (BOSCHETTI, 2011, p. 564).

Vale ressaltar que na última gestão do CFESS (triênio 2014-2017) foi iniciado um levantamento nacional das condições de trabalho dos/as Agentes Fiscais e da atual estruturação das COFIs, visando, assim, que ao final do processo seja elaborado um documento que institua os parâmetros mínimos para o funcionamento e estruturação da referida comissão em âmbito nacional. Entretanto, tal estudo ainda está sendo desenvolvido e não se tem previsão de quando será finalizado.

Isto posto, entendemos que esse estudo representa uma das tentativas que o CFESS, atuando de maneira articulada com os CRESS, vem desencadeando no sentido de dar relevância a essa situação peculiar dos/as Agentes Fiscais, buscando conhecer a realidade, vislumbrando disponibilizar condições éticas e técnicas adequadas para o exercício profissional deles/as em seus respectivos regionais.

\section{CONSIDERAÇÕES FINAIS}

O cenário atual de ofensiva do capital pela via da regressão dos direitos contribui decisivamente para o agravamento das diversas expressões da Questão Social que atingem a classe trabalhadora, com destaque para o aumento da pauperização e da desigualdade social em nosso país, evidenciando a sua face desumana e que não é possível haver garantia de direitos e emancipação humana plena sob os ditames do capital. O/a Assistente Social enquanto trabalhador/a assalariado/a também está submetido/a à essas consequências nos mais diversos espaços socioocupacionais de trabalho.

Nesse contexto, torna-se importante o devido investimento na melhoria das condições de trabalho dos/as Agentes Fiscais inseridos/as nos CRESS. Os aspectos éticos e técnicos, os equipamentos necessários para desenvolvimento das atividades, a condição salarial e de construção de uma carreira são requisitos indispensáveis para promover a continuidade da execução da Política Nacional de Fiscalização (PNF) com maior qualidade e, consequentemente, para o fortalecimento do projeto ético-político da profissão.

Portanto, entendemos que a fiscalização do exercício profissional dos/as Assistentes Sociais deve ser compreendida como uma ação estratégica para o fortalecimento da categoria articulando suas bandeiras de lutas às da classe trabalhadora por melhores condições salariais e objetivas de trabalho. E, ao mesmo tempo, ela contribui para o fortalecimento do projeto ético-político da profissão de Serviço Social que defende a superação da ordem societária atual por uma sociedade que possibilite a garantia de direitos e a plena emancipação humana.

\section{REFERÊNCIAS}

Temporalis, Brasília (DF), ano 18, n. 36, p. 320-335, jul./dez. 2018. ISSN 2238-1856 
fiscalização do exercício profissional dos/as assistentes sociais e suas peculiaridades tellpOP Olif

ABREU, Ana Cristina Muricy de. A Política Nacional de Fiscalização do Conjunto CFESSCRESS: avanços e particularidades. Revista Inscrita, Brasília (DF): CFESS, ano 9, n. 13, p. 5763, nov. 2012.

BOSCHETTI, Ivanete. Condições de trabalho e a luta dos (as) assistentes sociais pela jornada semanal de 30 horas. Revista Serviço Social e Sociedade, São Paulo, n. 107, p. 557584, jul./set. 2011.

BRASIL. Presidência da República. Decreto $n^{\circ}$ 994, de 15 de maio de 1962. Regulamenta a Lei $\mathrm{n}^{\circ}$ 3.252, de 27 de agosto de 1957, que dispõe sobre o exercício da profissão de Assistente Social. Brasília (DF), 1962.

BRASIL. Presidência da República. Lei No 8.662, de 7 de junho de 1993. Regulamentação da Profissão de Serviço Social. Brasília (DF), 1993.

CONSELHO FEDERAL DE SERVIÇO SOCIAL. Política Nacional de Enfrentamento à Inadimplência no Conjunto CFESS/CRESS. Brasília (DF), $2017 a$.

CONSELHO FEDERAL DE SERVIÇO SOCIAL-CONSELHOS REGIONAIS DE SERVIÇO SOCIAL. Sou assistente social e aqui estão minhas bandeiras de luta!: conheça a pauta política do serviço social brasileiro construpida coletivamente ao longo dos últimos anos pelo conjunto CFESS-CRESS. Brasília (DF), 2017b. Disponível em: <http://www.cfess.org.br/js/library/pdfjs/web/viewer.html?pdf=/arquivos/FolderBandeirad eLutas-Livreto.pdf $>$. Acesso em: 07 set. 2016.

CONSELHO FEDERAL DE SERVIÇO SOCIAL. Bandeiras de lutas do Conjunto CFESS/CRESS. Brasília (DF), 2016.

CONSELHO FEDERAL DE SERVIÇO SOCIAL. CFESS / CRESS - HISTÓRICO. Brasília (DF), 2015. Disponível em: <http://www.cfess.org.br/cfess_historico.php>. Acesso em: 7 set. 2016.

CONSELHO FEDERAL DE SERVIÇO SOCIAL. Resolução CFESS nº 512/2007. Brasília (DF), 2007.

CONSELHO FEDERAL DE SERVIÇO SOCIAL. Resolução CFESS n 493/2006. Brasília (DF), 2006.

CONSELHO FEDERAL DE SERVIÇO SOCIAL. Código de Ética do/a Assistente Social. Resolução n² 273. Brasília, DF: CFESS, 1993.

IASI, Mauro Luís. A Maldição e a Emancipação do Trabalho (Ou como a Humanidade Dançou e Como Ela Pode Dançar). In: LEWGOY, Alzira et al. Sociabilidade burguesa e Serviço Social. 1. ed. Rio de Janeiro: Lumen Juris, 2013, p. 45-61.

MOURÃO, Ana Maria Arreguy. Notas sobre o protagonismo dos Conselhos de Fiscalização no processo de renovação da profissão do Serviço Social, nos anos noventa. Libertas, Juiz de Fora, v. 2, 3, n. 1, 2, jan./jul./dez. 2001; 2003. p. 43-58.

PEREIRA, Ricardo Teixeira do Valle. Histórico dos Conselhos de Fiscalização do Exercício Profissional. In: MAURIQUE, Jorge Antonio et al. Conselhos de Fiscalização Profissional: 


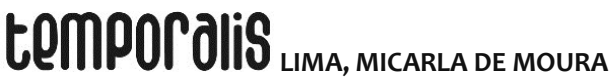

Doutrina e Jurisprudência. 3. ed. rev., atual. e ampl. São Paulo: Revista dos Tribunais, 2013a, p. 19-28.

PEREIRA, Ricardo Teixeira do Valle. Natureza Jurídica dos Conselhos de Fiscalização do Exercício Profissional. In: MAURIQUE et al. Conselhos de Fiscalização Profissional: Doutrina e Jurisprudência. 3. ed. rev., atual. e ampl. São Paulo: Revista dos Tribunais, 2013b, p. 29-57.

SANTOS, Josiane Soares et al. Fiscalização do exercício profissional e projeto ético-político. Serviço Social e Sociedade, São Paulo, n. 101, p.146-176, jan./mar. 2010.

VINAGRE, Marlise. A "Virada" na ética e nos Conselhos de Fiscalização Profissional. Serviço Social e Sociedade, São Paulo, n. 100, p. 720-727, out./dez. 2009. 